\title{
Executive function and metacognitive self-awareness after Severe Traumatic Brain Injury
}

\author{
UMBERTO BIVONA, ${ }^{1}$ PAOLA CIURLI,${ }^{1}$ CARMEN BARBA, ${ }^{2}$ GRAZIANO ONDER, ${ }^{3}$ \\ EVA AZICNUDA, ${ }^{1}$ DANIELA SILVESTRO,${ }^{1}$ RENATA MANGANO,${ }^{1}$ JESSICA RIGON,${ }^{1}$ \\ AND RITA FORMISANO ${ }^{1}$ \\ ${ }^{1}$ Post-Coma Unit, Fondazione Santa Lucia, Rome, Italy \\ 2Pediatric Neurology Unit, Children's Hospital “A. Meyer", Florence, Italy \\ ${ }^{3}$ Geriatric Department, Catholic University, Rome, Italy
}

(Received June 18, 2007; Final Revision June 6, 2008; AccePted June 6, 2008)

\begin{abstract}
The objective of this study is to identify the clinical, neuropsychological, neuropsychiatric, and functional variables that correlate with metacognitive self-awareness (SA) in severe traumatic brain injury (TBI) outpatients and to assess the influence of the same variables on the sensory-motor, cognitive, and behavioral-affective indicators of SA. This cross-sectional observational study evaluated 37 outpatients from May 2006 to June 2007 in a neurorehabilitation hospital on the basis of the following inclusion criteria: (1) age $\geq 15$ years; (2) diagnosis of severe TBI (Glasgow Coma Scale, GCS $\leq 8$ ); (3) posttraumatic amnesia (PTA) resolution; (4) capacity to undergo formal psychometric evaluation despite cognitive and sensory-motor deficits; (5) absence of aphasia; (6) availability of informed consent. A neuropsychological battery was used to evaluate attention, memory, and executive functions. SA was assessed by the awareness questionnaire (AQ), administered to both patients and relatives. Decreased metacognitive self-awareness is significantly correlated with increased problems in some components of executive system, even when the AQ subscales were considered separately. The significant correlation found between some components of executive system and metacognitive self-awareness confirmed the importance of addressing this issue to treat SA contextually in the rehabilitation of executive functions. (JINS, 2008, 14, 862-868.)
\end{abstract}

Keywords: Executive functions, Metacognitive self-awareness, Set shifting ability, Perseverative responses, TBI rehabilitation

\section{INTRODUCTION}

Self-awareness (SA), defined as the ability to recognize problems caused by damaged brain function, is commonly impaired in patients with traumatic brain injury (TBI) (BenYishay et al., 1985; Prigatano et al., 1986; Sherer et al., 2003a). Disturbance of SA may cause reduced motivation for rehabilitation (Malec \& Moessner, 2001) and may interfere with safe and independent functioning (Flashman et al., 1998), leading to poor outcome and difficulty with community integration (Trudel et al., 1998) and employability (Sherer et al., 2003b).

Correspondence and reprint requests to: Umberto Bivona, Unità postComa, Fondazione Santa Lucia, Via Ardeatina 306, 00179-Roma, Italy. E-mail: u.bivona@hsantalucia.it
Crosson et al. (1989) divided awareness into the following areas: intellectual awareness, which represents patients' ability to describe their deficits or impaired functioning; emergent awareness, which represents patients' ability to recognize their difficulties as they are happening; anticipatory awareness, which represents patients' ability to predict when difficulties will arise because of their deficits.

Recent studies have differentiated between metacognitive knowledge (or declarative knowledge) about one's abilities (which incorporates elements of intellectual awareness), and online monitoring of performance during tasks (which relates to emergent awareness and anticipatory awareness) (O'Keeffe et al., 2007; Toglia \& Kirk, 2000).

To assess metacognitive SA deficits (O'Keeffe et al., 2007) the most commonly used scales, that is, the Patient Competency Rating Scale (PCRS) (Prigatano et al., 1986) and 
the Dysexecutive Questionnaire (DEX) (Wilson et al., 1996), compare self-reports of competencies to reports of significant others.

As an alternative to these scales, Sherer et al. (1998) developed the Awareness Questionnaire (AQ), consisting of 17 items that evaluate patients' current functional abilities compared with their preinjury abilities. AQ items are rated on a Likert scale ranging from 1 (much worse) to 5 (much better). Scores vary from 17 to 85 , with a score of 51 indicating that the patient is functioning "about the same" as his/her preinjury level (Sherer et al., 2003a). Like the PCRS and the DEX, the AQ also includes forms for patient self ratings as well as family/significant other and clinician ratings. The degree of the SA deficit is calculated by subtracting family/ significant other ratings or clinician ratings from patient self ratings. These discrepancy scores can range from -68 to 68 . Higher discrepancy scores are associated with more severe SA deficits, while negative scores are rare and might show a patient's overestimation of his impairment (Cicerone, 1991; Prigatano \& Altman, 1990), possibly due to a high level of emotional distress (Fleming et al., 1998; Godfrey et al., 1993) or to the development of self-limiting belief systems in which TBI patients overrate the effects of their injury in everyday life (Moore \& Stambrook, 1995).

Reliability studies of the AQ revealed internal consistencies (Chronbach's $\alpha=0.88$ ) for both patient and family ratings; however, test-retest reliability has not been reported. Factor analysis of the AQ (Sherer et al., 1998) revealed three subscales: motor-sensory (four items), cognition (seven items), and behavioral-affective (six items).

However, whichever scales were used many issues about SA impairment in TBI patients are still being debated. Severity of brain injury correlated with measures of impaired awareness in some studies (Leathem et al., 1998; Prigatano \& Altman, 1990), but not in others (Anson \& Ponsford, 2006; Bach \& David, 2006; O'Keeffe et al., 2007; Port et al., 2002).

Also, the correlation between SA deficits and neuropsychological disturbances is not clear (Allen \& Ruff, 1990; Boake et al., 1995) even if executive functions (EF), in particular, are frequently impaired in TBI patients (Mattson \& Levin, 1990; Stablum et al., 1996) and are considered to influence degree of SA following brain damage (Hart et al., 2005; Noè et al., 2005).

EF are part of a very complex system that includes behavioral, affective, motivational, and cognitive components (Apollonio et al., 2005). Cognitive disorders suggestive of the dysexecutive syndrome include response initiation and response suppression, focused attention, maintenance and shifting of set, rule deduction, problem solving and planning, and information generation (Apollonio et al., 2005). As a consequence, there is no comprehensive test for the executive system and many tests have been proposed to analyze its single aspects. However, it has been demonstrated that the Wisconsin Card Sorting Test (WCST) is an effective measure of multiple components, such as abstract reasoning, and that it provides data on problem solving, the ability to use response feedback information, the cognitive flexibility, set-shifting and set-persistence capacity, concept identification, hypothesis generation (Hanks et al., 1999; Mukhopadhyay et al., 2008). In particular, in this test perseverative errors have been shown to be an excellent measure of executive dysfunction (Johnstone et al., 1995).

In exploring EF, the Verbal Fluency (VF) test also engages several cognitive processes such as working memory, selfmonitoring, and cognitive flexibility (Schwartz et al., 2003); another well-established test, the Tower of London (ToL) (Unterrainer \& Owen, 2006), has been used extensively to evaluate planning ability in patients with neuropsychological disorders and in control subjects.

Many authors have tried to correlate executive dysfunction with impaired SA in TBI patients, but no conclusive findings have been reported. Bach and David (2006), who investigated SAdeficits by means of the PCRS, failed to demonstrate that EF disorders (explored by the VF Test, the Trial Making Test and the Gambling Task) are associated with reduced behavioral/social SA. Conversely, using the DEX and the Self Awareness of Deficit Interview (SADI) (Fleming et al., 1996) to evaluate SA deficits, Bogod et al. (2003) found a correlation between the dysexecutive syndrome (diagnosed by means of the Go-no-go Task, the Victoria Stroop Test, and the Self-ordered Pointing Test-SOPT ) and unawareness. In a group of 31 patients with TBI, O'Keeffe et al. (2007) showed that low SA and high SA groups did not differ on any standard neuropsychological task, but that those with low SA were more likely to exhibit disinhibition, interpersonal problems, and greater difficulty in overall competency.

Finally, Noè et al. (2005) evaluated EF by means of the WCST, the Color Trial Making Test and the VF Test and demonstrated a significant correlation between poor WCST performance and low SA (assessed by the PCRS) in a heterogeneous acquired brain injury population in which both professionals and family members were enrolled as significant others.

The purpose of the present study was to identify the clinical, neuropsychological, neuropsychiatric, and functional variables that correlate with metacognitive self-awareness (SA) in severe traumatic brain injury (TBI) outpatients. Also, the influence of the same indicators on the sensorymotor, cognitive, and behavioral-affective domains of the SA scale was investigated separately.

\section{METHODS}

\section{Participants}

A total of 40 consecutive severe TBI outpatients were enrolled from May 2006 to June 2007 in the Post-Coma Unit of Santa Lucia Foundation, a neurorehabilitation hospital and research institute in Rome. The study was approved by the Santa Lucia Foundation ethical committee.

The study sample was recruited from an overall sample of 76 outpatients evaluated in that period on the basis of the following inclusion and exclusion criteria: inclusion crite- 
ria: (1) age $\geq 15$ years; (2) diagnosis of severe TBI (GCS $\leq$ 8; Teasdale \& Jennett, 1974); (3) posttraumatic amnesia (PTA) resolution; (4) capacity to undergo formal psychometric evaluation despite cognitive and sensory-motor deficits; (5) absence of aphasia; (6) availability of informed consent; exclusion criteria: previous history of drug and alcohol addiction, psychiatric diseases, and repeated TBI.

Three patients were excluded after enrollment because they refused to complete the test battery (one patient because of an excessive and unexpected fatigability; the other two because of low tolerance of frustration).

Finally, we evaluated 37 patients, 29 males $(78 \%)$ and 8 females $(22 \%)$, with a mean age of $32.3 \pm 11.6$ years and a mean of $12.6 \pm 3.1$ years of education. The median interval in years from injury to date of assessment (chronicity) was 0.69 (Interquartile Range, IQR: 0.45/8.52). All patients had severe TBI with a median time to follow commands (TFC coma duration) of 20 days (IQR: 12/40) and a median PTA length of 60 days (IQR: 40/140). TFC was defined as the interval, in days, from coma onset until the patient was able to follow simple commands. PTA was evaluated prospectively by means of the Galveston Orientation and Amnesia Test (GOAT) (Levin et al., 1979) in 23 patients, who were previously hospitalized in our rehabilitation unit as inpatients. It was calculated retrospectively, on the basis of information given by patients and family members, for the last 14 patients who had already recovered from PTA at the time of admission to our rehabilitation hospital. In fact, since it has been reported that retrospective analysis is correlated ( $r=0.87$ ) with prospective investigation of PTA (McMillan et al., 1996), retrospective and prospective evaluations of PTA were considered equivalent.

\section{Assessment}

A neuropsychological battery was administered to all patients and the following assessment was made: memory: Digit Span Test (forward and backward) (Orsini, 2003), Prose Memory Test (Novelli et al., 1986); executive functioning: WCST (Heaton et al., 1993, 2000), ToL (Krikorian et al., 1994), VF Test (Novelli et al., 1986); attention: Go-No Go Test of the Test Batterie zur Aufmerksamkeitsprüfung (Zimmerman \& Fimm, 1992).

Neuropsychiatric disturbances were evaluated by means of the Neuropsychiatric Inventory (NPI) (Cummings, 1994). Functional assessment included the following scales: the Disability Rating Scale (DRS) (Rappaport et al., 1982), the Levels of Cognitive Functioning Scale (LCF-S) (Hagen et al., 1972), and the Glasgow Outcome Scale Extended (GOS-E) (Wilson et al., 1998).

SA level was measured by means of AQ, which was completed by both the patient and a family member in all cases. Only first-degree relatives who were living with patients or at least had daily contact with them were enrolled. Scores obtained by patients and family members on each AQ subscale were calculated as well. Possible SA deficits were evaluated according to the discrepancy between self rating and family rating (Ownsworth et al., 2007; Pagulayan et al., 2007; Prigatano, 1996; Sherer et al., 1998; Walker et al., 1987). We chose relatives instead of the clinician as significant other raters because the former are in the best position to judge the patient's functional ability in daily life, especially compared with his/her premorbid functioning.

In previous reports (Noè et al., 2005; Sherer et al., 2003a) a cutoff point for severity of SA deficits, based on different probabilities of employability associated with patientclinician discrepancy, was established for the AQ. We decided not to use this cutoff point because in our study the "significant other" was always a member of the patient's family, not the clinician.

\section{Statistical Analysis}

AQ discrepancy scores for the questionnaire as a whole and for each subscale were computed by subtracting the relative rating from the patient's self rating. Pearson's correlation coefficients were calculated to study the correlation between AQ discrepancy scores and single variables. For these analyses, $p$ values were calculated using Hommel's multiple-comparison procedure (Hommel, 1988). A value of $p$ below 0.05 (two-tail) was considered statistically significant. All analyses were performed using SPSS for Windows, version 10.0.

\section{RESULTS}

Table 1 shows the distribution of neuropsychological data, in terms of means, medians, and IQR range.

When all patients' AQ data was considered, a discrepancy (which ranged from -18 to 28 ) was detected between self ratings and relative ratings. Negative scores were found in 9 patients who were well preserved cognitively. Discrepancy was higher for the behavioral-affective and cognitive subscales than for the sensory-motor subscale. Data regarding the AQ scale and subscales are shown in Table 2.

There were no significant correlations between the AQ patient-relative discrepancy scores and the clinical and functional variables (see Table 3 ).

Conversely, the AQ discrepancy score was significantly correlated with the WCST number of categories completed $(p=.027)$ and the WCST perseverative responses ( $p=$ .005 ), but not with the WCST nonperserverative errors ( $p=$ .26). None of the other neuropsychological variables analyzed correlated with the AQ discrepancy scores.

As shown in Table 4, correlations between the WCST variables and the AQ discrepancy scores were substantially confirmed for the AQ discrepancy subscores. In particular, the correlations seemed stronger for the cognitive subscale than for the behavioral-affective and sensorymotor subscales.

\section{DISCUSSION}

The main result of this study was the following: decreased metacognitive self-awareness is significantly correlated with 
Table 1. Distribution of neuropsychological data

\begin{tabular}{lccc}
\hline \hline & Mean & Median & IQR \\
\hline Executive Functions & & & \\
WCST: numbers of categories completed & 5.1 & 6 & $4.5 / 6$ \\
WCST: \% perseverative responses & 15.3 & 12.0 & $7.0 / 19.5$ \\
WCST: \% non perseverative errors & 11.7 & 9.0 & $7.0 / 16.2$ \\
Tower of London & 30.5 & 31 & $29.5 / 33$ \\
$\quad$ Verbal fluency: phonemic categories & 21.1 & 21 & $14 / 29.5$ \\
Attention & & & \\
$\quad$ Selective attention-total false responses & 38.5 & 46 & $35 / 50$ \\
Memory & & & \\
$\quad$ Working memory & 8.6 & 9 & $7 / 11$ \\
$\quad$ Prose memory & 9.4 & 10 & $6 / 12.5$ \\
\hline \hline
\end{tabular}

Note. WCST, Wisconsin Card Sorting Test.

increased problems in some components of executive system, even when the AQ subscales were considered separately.

Consistent with previous studies (Bach \& David, 2006; Borgaro \& Prigatano, 2002; Leathem et al., 1998; Noè et al., 2005; O’Keeffe et al., 2007; Port et al., 2002; Prigatano \& Altman, 1990), we found no correlation between either the SA and chronicity or between the SA and length of PTA.

Conversely, in agreement with Noè et al. (2005) our findings demonstrate a significant correlation between some components of executive functions (flexibility and ability to inhibit the response, ability to benefit from feedback, shifting of set, problem solving), assessed by the WCST, and the metacognitive SA. Unlike that study, we used the AQ (instead of the PCRS), because it compares patients' current functional ability with their preinjury condition. We enrolled only relatives as significant others, rather than professionals or family members, as in the study by Noè et al. Moreover, our sample was more homogeneous because all subjects were severe TBI outpatients who had recovered from PTA and were able to answer the questionnaires reliably; in the study by Noè et al. instead, the patients had sustained different types of acquired brain injury, TBI was not severe in all cases, and some of them were still in PTA.

Our findings expand upon the results of Noè et al. (2005) on the correlation between pathological number of categories and low SA. In fact, we found a correlation between low SA levels and pathological number of categories completed and percentage of perseverative responses, which is a well-known index of poor flexibility and inability to inhibit the response (Johnstone et al., 1995).

Considering the significant correlation between the abovementioned WCST scores and the low metacognitive SA levels, the lack of any relationship between AQ scores and other measures of EF, such as the VF Test and the ToL scores, is worth noting. Perhaps this was due to the fact that the different tests used to assess EF measure different aspects of these functions. While a successful performance on WCST requires some abilities as the cognitive flexibility, setshifting and set-persistence capacity, concept identification, hypothesis generation, and the ability to use response feedback information (Mukhopadhyay et al., 2008), the ToL, particularly in the version used in the present study (Krikorian et al., 1994), primarily assesses planning and problem solving (Unterrainer \& Owen, 2006). Moreover, it has been pointed out that while the WCST and the VF Test discriminate clearly between severe TBI patients and control subjects, the ToL test does not (Cockburn, 1995). Furthermore, although poor performance on VF tests is generally interpreted as reflecting executive dysfunction (Phillips, 1999) and suggesting frontal lobe damage (Benton, 1968), little is known about the cognitive processes involved in fluency tasks (Light, 1992; Randolph et al., 1993).

The correlations between SA and EF were further analyzed using DEX (Wilson et al., 1996), a significant other scale which investigates the awareness of cognitive, affective, and behavioral aspects of the dysexecutive syndrome. When Bogod et al. (2003) compared the DEX question-

Table 2. AQ scale and subscale discrepancy scores

\begin{tabular}{lccccrr}
\hline \hline & Mean & SD & Median & IQR & Min & Max \\
\hline AQ total score & 5.7 & 9.8 & 5.0 & $-1.0 / 11.5$ & -18 & 28 \\
AQ_behavioral/affective & 1.7 & 4.0 & 1.0 & $-1.0 / 3.0$ & -8 & 13 \\
AQ_cognitive & 3.0 & 4.7 & 3.0 & $0 / 6.5$ & -9 & 13 \\
AQ_sensory/motor & 0.9 & 2.0 & 1.0 & $-1.0 / 3.0$ & -4 & 4 \\
\hline \hline
\end{tabular}

Note. $\mathrm{AQ}=$ Awareness Questionnaire. 
Table 3. Correlations of clinical and neuropsychological data with AQ discrepancy score

\begin{tabular}{lrl}
\hline \hline Variable & Pearson $r$ & $p$ value* \\
\hline Clinical data & -0.141 & 1 \\
Age, years & 0.208 & 1 \\
Chronicity, years & 0.236 & 0.91 \\
Length of PTA, days & 0.030 & 1 \\
DRS & -0.281 & 0.70 \\
LCF & -0.120 & 1 \\
GOS-E & & \\
Neuropsychological data & & \\
Executive functions & -0.511 & $0.027^{*}$ \\
$\quad$ WCST: numbers of categories & & \\
$\quad$ completed & 0.590 & $0.005^{* *}$ \\
$\quad$ WCST: perseverative responses & 0.390 & 0.26 \\
$\quad$ WCST: nonperseverative errors & -0.237 & 0.91 \\
Tower of London & -0.318 & 0.60 \\
$\quad$ Verbal fluency: phonemic & & \\
$\quad$ categories & & \\
Attention & -0.076 & 1 \\
$\quad$ Selective attention-total false & & \\
$\quad$ responses & -0.058 & 1 \\
Memory & -0.306 & 0.60 \\
$\quad$ Working memory & & \\
Prose memory & & \\
\hline \hline
\end{tabular}

Note. PTA $=$ Post-Traumatic Amnesia; DRS $=$ Disability Rating Scale; LCF $=$ Levels of Cognitive Functioning; GOS-E = Glasgow Outcome Scale Extended; WCST $=$ Wisconsin Card Sorting Test. $* p<0.05$.

$* * p<0.01$.

The $p$ values were calculated using Hommel's multiple-comparison procedure.

naire and the SADI (Fleming et al., 1996) with tests of EF and intelligence quotient (IQ), they found that the SADI correlated better than the DEX with measures of frontal lobe functioning and injury severity. Moreover, Hart et al. (2005) performed a composite EF assessment (called executive composite, EC) and showed that individuals with TBI who had low EC scores had statistically significant worse SA than controls when assessed by DEX. In our opinion, the present study is not comparable with these previous reports because we investigated different aspects of the exec- utive system and evaluated awareness using different approaches.

Awareness is not a unitary concept and aspects of awareness can be differentiated and linked to different areas of daily functioning. In fact, the correlation between EF deficits and impaired SA was still present even when different AQ subscales were considered, confirming the close relationship between these cognitive functions and SA. Moreover, our data seem to indicate that SA is more impaired with respect to cognitive and social-emotional components and less impaired for physical deficits.

Our study presents some limitations. We included a sample of family members whose ratings may have been unreliable because of their high distress levels (Fleming et al., 1996), also due to the patient's chronicity. In fact, the longterm of the caregiver efforts to cope with the posttrauma condition and the change of quality of their previous/ current relationship with the patient worsen with time, because of the lack of further improvement. However, we chose relatives instead of the clinician as significant other raters because the former are in the best position to compare the patient's functional ability in daily life with his/ her premorbid functioning, as required by the AQ. Moreover, as only outpatients were included in our study sample, relatives were presumably able to provide more accurate information about performance because they were familiar with the patient's personality.

We preferred to use the AQ instead of the PCRS to evaluate the functional implications of postinjury deficits in determining life changes after TBI because it compares patients' current functional abilities with their preinjury ones; in fact, there are no previous reports of the use of this scale to measure SA compared with patient's premorbid condition. On the other hand, as we did not include an additional "gold standard" measure, such as the PCRS, to provide concurrent validity, only a comparative analysis between the PRCS and the AQ would be able to provide conclusive results.

The present study is also limited by the small sample size, which may not have sufficient power to detect associations between clinical and functional variables and SA.

Studies based on larger samples are needed to investigate more thoroughly the neuropsychological disorders corre-

Table 4. Correlations of WCST with AQ discrepancy subscores

\begin{tabular}{|c|c|c|c|}
\hline & $\begin{array}{c}\text { Behavioral/ } \\
\text { affective subscale }\end{array}$ & $\begin{array}{l}\text { Cognitive } \\
\text { subscale }\end{array}$ & $\begin{array}{c}\text { Sensory-motor } \\
\text { subscale }\end{array}$ \\
\hline & $r$ & $r$ & $r$ \\
\hline WCST: $n$ of categories completed & -0.385 & $-0.576 * *$ & -0.368 \\
\hline WCST: perseverative responses & $0.470 *$ & $0.611 * *$ & $0.500 *$ \\
\hline WCST: non perseverative errors & 0.344 & 0.369 & 0.340 \\
\hline
\end{tabular}


lated with SA deficits and the possibility that the correlation between SA deficits and executive dysfunction depends on anatomical coincidence, as the frontal lobes are involved in both EF and SA. Moreover, it would be important to focus on a multidimensional assessment of awareness across the three levels of SA, as outlined by different clinical models (Crosson et al., 1989; Toglia \& Kirk, 2000) and suggested by O'Keeffe et al. (2007).

However, the significant correlation between EF and metacognitive SA strongly suggests the importance of integrating an overall assessment of cognitive functions with a specific evaluation of self-awareness and of treating selfawareness contextually in a structured comprehensive rehabilitation program (Port et al., 2002). In fact, the inclusion of self-awareness in a multi-disciplinary rehabilitation program (Dirette, 2002) might enhance patients' self-awareness and participation in cognitive and functional tasks.

\section{REFERENCES}

Allen, C.C. \& Ruff, R.M. (1990). Self-rating versus neuropsychological performance of moderate versus severe head-injured patients. Brain Injury, 4, 7-17.

Anson, K. \& Ponsford, J. (2006). Who benefits? Outcome following a coping skills group intervention for traumatically brain injured individuals. Brain Injury, 20, 1-13.

Apollonio, I., Leone, M., Isella, V., Piamarta, F., Consoli, T., Villa, M.L., Forapani, E., Russo, A., \& Nichelli, P. (2005). The Frontal Assessment Battery (FAB): Normative values in an Italian population sample. Journal of the Neurological Sciences, 26, 108-116.

Bach, L.J. \& David, A.S. (2006). Self-awareness after acquired and traumatic brain injury. Neuropsychological Rehabilitation, 16, 397-414.

Benton, A.L. (1968). Differential behavioural effects of frontal lobe disease. Neuropsychologia, 6, 53-60.

Ben-Yishay, Y., Rattok, J., Lakin, P., Piasetsky, E.B., Ross, B., Silver, S., Zide, E., \& Ezrachi, O. (1985). Neuropsychological rehabilitation: Quest for a holistic approach. Seminars in Neurology, 5, 252-259.

Boake, C., Freeland, J.C., Ringholz, G.M., Nance, M.L., \& Edwards, K.E. (1995). Awareness of memory loss after severe closedhead injury. Brain Injury, 9, 273-83.

Bogod, N.M., Mateer, C.A., \& MacDonald, S.W. (2003). Selfawareness after traumatic brain injury: A comparison of measures and their relationship to executive functions. Journal of the International Neuropsychological Society, 9, 450-458.

Borgaro, S. \& Prigatano, G. (2002). Early cognitive and affective sequelae of traumatic brain injury: A study using the BNI screen for higher cerebral functions. Journal of Head Trauma Rehabilitation, 17, 526-534.

Cicerone, K.D. (1991). Psychotherapy after mild traumatic brain injury: Relation to the nature and severity of subjective complaints. Journal of Head Trauma Rehabilitation, 6, 30-43.

Cockburn, J. (1995). Performance on the Tower of London Test after severe head injury. Journal of the International Neuropsychological Society, 1, 537-544.

Crosson, C., Barco, P.P., Velozo, C., Bolesta, M.M., Cooper, P.V., Werts, D., \& Brobeck, T.C. (1989). Awareness and compensa- tion in postacute head injury rehabilitation. Journal of Head Trauma Rehabilitation, 4, 46-54.

Cummings, J.L. (1994). Neuropsychiatric inventory. Neurology, 44, 2308-2314.

Dirette, D. (2002). The development of awareness and the use of compensatory strategies for cognitive deficits. Brain Injury, $16,861-871$.

Flashman, L.A., Amador, X., \& McAllister, T.W. (1998). Lack of awareness of deficit in traumatic brain injury. Seminars in Clinical Neuropsychiatry, 3, 201-210.

Fleming, J.M, Strong, J., \& Ashton, R. (1996). Self-awareness of deficits in adults with traumatic brain injury: How best to measure? Brain Injury, 10, 1-15.

Fleming, J.M., Strong, J., \& Ashton, R. (1998). Cluster analysis of self-awareness levels in adult with traumatic brain injury and relationship to outcome. Journal of Head Trauma Rehabilitation, 13, 39-59.

Godfrey, H.P., Partridge, F.M., Knight, R.G., \& Bishara, S. (1993). Course of insight disorder and emotional dysfunction following closed head injury: A controlled cross-sectional follow-up study. Journal of Clinical and Experimental Neuropsychology, $15,503-515$.

Hagen, C., Malkmus, D., \& Durham, P. (1972). Levels of Cognitive Functioning. Downey, CA: Rancho Los Amigos Hospital.

Hanks, R.B., Rappaport, L.J., Millis, S.R., \& Deshpande, S.A. (1999). Measures of executive functioning as predictors of functional ability and social integration in a rehabilitation sample. Archives of Physical Medicine and Rehabilitation, 80, 1030-1036.

Hart, T., Whyte, J., Kim, J., \& Vaccaro, M. (2005). Executive function and self-awareness of "real-world" behavior and attention deficits following traumatic brain injury. Journal of Head Trauma Rehabilitation, 20, 333-347.

Heaton, R.K., Chelune, G.J., Talley, J.L., Kay, G.G., \& Curtiss, G. (1993). Wisconsin Card Sorting Test. Florida: Psychological Assessment Resources, Inc.

Heaton, R.K., Chelune, G.J., Talley, J.L., Kay, G.G., \& Curtiss, G. (2000). WCST: Wisconsin Card Sorting Test. Forma completa revisionata. Adattamento Italiano a cura di Hardoy, M.C., Carta, M.G., Hardoy, M.J., e Cabras, P.L., in O.S. Organizzazioni Speciali (Eds.) it. Firenze, Italy.

Hommel, G. (1988). A stagewise rejective multiple test procedure based on a modified Bonferroni test. Biometrika, 75, 383-386.

Johnstone, B., Hexum, C.L., \& Ashkanazi, G. (1995). Extend of cognitive deficit in traumatic brain injury based on estimates of premorbid intelligence. Brain Injury, 9, 377-384.

Krikorian, R., Bartok, J., \& Gay, N. (1994). Tower of London Procedure: A standard method and developmental data. Journal of Clinical and Experimental Neuropsychology, 16, $840-850$.

Leathem, J.M., Murphy, L.J., \& Flett, R.A. (1998). Self- and informant ratings on the Patient Competency Rating Scale in patients with traumatic brain injury. Journal of Clinical and Experimental Neuropsychology, 20, 694-705.

Levin, H.S., O'Donnel, V.M., \& Grossman, R.G. (1979). The Galveston Orientation and Amnesia test: A practical scale to assess cognition after head injury. The Journal of Nervous and Mental Disease, 167, 675-84.

Light, L.L. (1992). The organization of memory in old age. In F.I.M. Craik \& T.A. Salthouse (Eds.), The Handbook of Aging and Cognition. Hillsdale, NJ: Lawrence Erlbaum Associates Inc. 
Malec, J.F. \& Moessner, A.M. (2001). Self-awareness, distress, and postacute rehabilitation outcome. Rehabilitation Psychology, 45, 227-241.

Mattson, A.J. \& Levin, H.S. (1990). Frontal lobe dysfunction following closed head injury. A review of the literature. The Journal of Nervous and Mental Disease, 178, 282-291.

McMillan, T.M., Jongen, E.L., \& Greenwood, R.J. (1996). Assessment of post-traumatic amnesia after severe closed head injury: Retrospective or prospective? Journal of Neurology, Neurosurgery, and Psychiatry, 60, 422-427.

Moore, A.D. \& Stambrook, M. (1995). Cognitive moderators of outcome following traumatic brain injury: A conceptual model and implications for rehabilitation. Brain Injury, 9, 109-130.

Mukhopadhyay, P., Dutt, A., Das, S.K., Basu, A., Hazra, A., Dhibar, T., \& Roy, T. (2008). Identification of neuroanatomical substrates of set-shifting ability: Evidence from patients with focal brain lesions. Progress in Brain Research, 168, 95-104.

Noè, E., Ferri, J., Caballero, M.C., Villadre, R., Sanchez, A., \& Chirivella, J. (2005). Self-awareness after acquired brain injury. Predictors and rehabilitation. Journal of Neurology, 252, 168-175.

Novelli, G., Papagno, C., Capitani, E., Laiacona, M., Vallar, G., \& Cappa, S.F. (1986). Tre test clinici di ricerca e produzione lessicale. Taratura su soggetti normali. Archivio di Psicologia, Neurologia e Psichiatria, 47, 477-506.

O'Keeffe, F., Dockree, P., Moloney, P., Carton, S., \& Robertson, I.H. (2007). Awareness of deficits in traumatic brain injury: A multidimensional approach to assessing metacognitive knowledge and online-awareness. Journal of the International Neuropsychological Society, 13, 38-49.

Orsini, A. (2003). La memoria diretta e la memoria inverse di cifre in soggetti dai 16 ai 64 anni. Bollettino di Psicologia Applicata, 239, 73-77.

Ownsworth, T., Fleming, J., Strong, J., Radel, M., Chan, W., \& Clare, L. (2007). Awareness typologies, long-term emotional adjustment and psychosocial outcomes following acquired brain injury. Neuropsychological Rehabilitation, 17, 129-150.

Pagulayan, K.F., Temkin, N.R., Machamer, J.E., \& Dikmen, S.S. (2007). The measurement and magnitude of awareness difficulties after traumatic brain injury: A longitudinal study. Journal of the International Neuropsychological Society, 13, 561-570.

Phillips, L.H. (1999). Age and individual differences in letter fluency. Developmental Neuropsychology, 15, 249-267. [http:// cat.inist.fr $/$ ?aModele $=$ afficheN\&cpsidt $=1780506]$

Port, A., Willmott, C., \& Charlton, J. (2002). Self-awareness following traumatic brain injury and implications for rehabilitation. Brain Injury, 16, 277-289.

Prigatano, G.P. (1996). Behavioral limitations TBI patients tend to underestimate: A replication and extension to patients with lateralized cerebral dysfunction. The Clinical Neuropsychologist, 10, 191-201.

Prigatano, G.P. \& Altman, I.M. (1990). Impaired awareness of behavioral limitations after traumatic brain injury. Archives of Physical Medicine and Rehabilitation, 71, 1058-1064.
Prigatano, G.P., Fordyce, D.J., Zeiner, H.K., Roueche, J.R., Pepping, M., \& Wood, B.C. (1986). Neuropsychological rehabilitation after brain injury. Baltimore: Johns Hopkins University Press.

Randolph, C., Braun, A.R., Goldberg, T.E., \& Chase, T.N. (1993). Semantic fluency in Alzheimer's, Parkinson's and Huntingdon's disease: Dissociation of storage and retrieval failures. Neuropsychology, 7, 82-88.

Rappaport, M., Hall, K.M., Hopkins, H.K., Belleza, T., \& Cope, D.N. (1982). Disability rating scale for severe head trauma: Coma to community. Archives of Physical Medicine and Rehabilitation, 63, 118-123.

Schwartz, S., Baldo, J., Graves, R.E., \& Brugger, P. (2003). Pervasive influence of semantics in letter and category fluency: A multidimensional approach. Brain and Language, 87, 400-411.

Sherer, M., Bergloff, P., Boake, C., High, W., Jr., \& Levin, E. (1998). The Awareness Questionnaire: Factor structure and internal consistency. Brain Injury, 12, 63-68.

Sherer, M., Hart, T., \& Nick, T.G. (2003a). Measurement of impaired self-awareness after traumatic brain injury: A comparison of the patient competency rating scale and the awareness questionnaire. Brain Injury, 17, 25-37.

Sherer, M., Hart, T., Nick, T.G., Whyte, J., Thompson, R.N., \& Yablon, S.A. (2003b). Early impaired self-awareness after traumatic brain injury. Archives of Physical Medicine and Rehabilitation, 84, 168-176.

Stablum, F., Mogentale, C., \& Umiltà, C. (1996). Executive functioning following mild closed head injury. Cortex, 32, 261-278.

Teasdale, G. \& Jennett, B. (1974). Assessment of coma and impaired consciousness. A practical scale. Lancet, 13, 81-84.

Toglia, J. \& Kirk, U. (2000). Understanding awareness deficits following brain injury. Neurorehabilitation, 15, 57-70.

Trudel, T.M., Tyron, W., \& Purdum, C. (1998). Awareness of disability and long-term outcome after traumatic brain injury. Rehabilitation Psychology, 43, 276-281.

Unterrainer, J. \& Owen, A.M. (2006). Planning and problem solving: From neuropsychology to functional neuroimaging. Journal of Psychology-Paris, 99, 308-317.

Walker, D.E., Blankenship, V., Ditty, J.A., \& Lynch, K.P. (1987). Prediction of recovery for closed-head-injured adults: An evaluation of the MMPI, the Adaptive Behavior Scale, and a "Quality of life" Rating Scale. Journal of Clinical Psychology, 43 , 699-707.

Wilson, B., Alderman, N., Burgess, P., Esmlie, H., \& Evans, J. (1996). Behavioral Assessment of the Dysexecutive Syndrome $(B A D S)$. Bury St. Edmunds, Suffolk, UK: Thames Valley Test Company.

Wilson, J.T., Pettigrew, L.E., \& Teasdale, G.M. (1998). Structured interviews for the Glasgow Outcome Scale and the Extended Glasgow Outcome Scale: Guidelines for their use. Journal of Neurotrauma, 15, 573-585.

Zimmerman, P. \& Fimm, B. (1992). Test Batterie zur Aufmerksamkeitsprüfung (TAP). Würselen, Germany: Psytest. 